\title{
Exposure to cigarette promotions and smoking uptake in adolescents: evidence of a dose-response relation
}

\author{
James D Sargent, Madeline Dalton, Michael Beach
}

\begin{abstract}
Objective-To assess whether a doseresponse relation exists between the number of cigarette promotional items (CPIs) owned by an adolescent, and smoking behaviour.

Design and setting-Voluntary, self administered survey of 1265 sixth through to 12 th grade students (ages 10-19 years), representing $79-95 \%$ of all students attending five rural New Hampshire and Vermont public (state funded) schools in October 1996. The association between the number of CPIs owned by students and smoking behaviour was examined using multivariate regression methods.
\end{abstract}

Outcome measures-Adjusted odds of being a smoker ( $\geqslant 100$ cigarettes lifetime) and, among never and experimental smokers, adjusted cumulative odds of having higher levels on a smoking uptake index given the number of CPIs owned.

Results-One third of students owned a CPI (n = 406). Among owners, 211 owned one, 82 owned two, 57 owned three, 24 owned four, 23 owned five, and 7 students owned six CPIs. The number of CPIs owned by students was not associated with grade in school but was significantly higher in males, those with poorer school performance, those who perceived high prevalence of peer smoking, and those with higher exposure to peer and family smoking. The more items a student owned, the greater the chances of being a smoker. For example, smoking prevalence was $11.2 \%$ for those not owning a CPI, $41.5 \%$ for those owning two, $58.5 \%$ for those owning four, and $71.4 \%$ for those owning six CPIs. The dose-response relation remained after controlling for confounding; compared with those who did not own a CPI, the likelihood of being a smoker was significantly higher for those who owned one CPI, with an adjusted odds ratio (OR) of 2.7 (95\% confidence interval (CI) 1.7 to 4.1); OR was $3.4(95 \%$ CI 1.9 to 5.9$)$ for those owning two CPIs, and $8.4(95 \%$ CI 5.0 to 14.2$)$ for those owning three or more CPIs. After excluding smokers, there was a crude dose-response association between CPI ownership and higher rates of experimentation with cigarettes among sixth to ninth graders (ages 11-15 years) only $(n=543)$. After controlling for confounding influ- ences, the dose-response relation remained, with the likelihood of being higher on the smoking uptake index rising with the number of CPIs owned: one CPI, adjusted cumulative OR 1.7 (95\% CI 1.1 to 2.60); two CPIs, OR 2.5 (95\% CI 1.2 to 5.1); and three or more CPIs, OR 4.8 (95\% CI 1.9 to 12.2 ).

Conclusions-This study offers evidence of a dose-response relation between the number of CPIs owned by adolescents and higher likelihood of experimental and established smoking. The dose-response relation persists after controlling for confounding influences. These data provide further support of a causal relation between tobacco promotional campaigns and smoking behaviour among adolescents.

(Tobacco Control 2000;9:163-168)

Keywords: adolescents; epidemiology; tobacco marketing

Current marketing practices by the tobacco industry may be contributing to the increased rates of smoking among children. Although the industry has denied intent to advertise and promote cigarettes to children, ${ }^{1}$ company documents indicate that this may not be the case. $^{2}$ Evidence of a causal relation between exposure to cigarette marketing (the epidemiological equivalent to exposure) and smoking initiation (the epidemiological equivalent to disease) exists if a significant association can be established between marketing and initiation; if the results are not explained by chance, bias, or confounding; if the findings are consistent with adolescent behavior theory; and if the findings can be replicated. ${ }^{3}$ Causality is strengthened if it can be established that the exposure precedes the behaviour and there is a dose response, with higher levels of exposure resulting in higher likelihood of the outcome.

The evidence from a number of cross sectional $^{4-7}$ and longitudinal studies $^{8}{ }^{9}$ of independent samples of children indicate that tobacco promotions are causally implicated in adolescents' decisions to begin smoking and in their continued experimentation with cigarettes. One research group has shown a dose-response to a five point index termed "receptivity to tobacco promotions", which measures the degree to which the respondent identifies and responds to tobacco marketing messages. ${ }^{9}$ This dose-response relation supports a communication based mechanism for 
the effect of tobacco promotions on smoking, in that a higher level of responsiveness by adolescents is associated with a higher level of smoking uptake.

The aim of this study is to evaluate dose-response within the highest category of the previously developed receptivity to advertising index, ownership of cigarette promotional items. We reported a cross sectional study in which ownership of cigarette promotional items (CPIs) was associated with higher levels of experimental and established smoking among rural Vermont and New Hampshire adolescents. ${ }^{6}$ In this analysis, we evaluate whether or not there is a dose-response between the number of CPIs owned by an adolescent and his/her likelihood of experimental and established smoking.

\section{Methods}

The methodology of this study and analysis is reported in detail elsewhere. ${ }^{6}$ Briefly, five rural schools in Vermont and New Hampshire participated in this survey. We chose low income rural communities because they represent populations at highest risk for tobacco use. ${ }^{10}$ Of five schools surveyed in October 1996, three were in New Hampshire (school A, grades 9-12, 469 students; school B, grades 6-7, 169 students; school C, grades 8-12, 378 students) and two were in Vermont (school D, grades 7-12, 288 students; school E, grades 7-12, 543 students).

Students in participating schools were asked to complete voluntarily an anonymous, self administered questionnaire in a classroom or assembly setting. Passive parental consent was obtained for the administration of this survey in school by mailing consent forms to students' homes 1-2 weeks before the survey date. The study and consent procedures were approved by the Dartmouth College committee for the protection of human subjects.

STUDENT SAMPLE

Completed questionnaires were obtained from 1543 students, representing $79-95 \%$ of the students in each school. Following procedures of Stevens and colleagues, ${ }^{11} 107$ (6.9\%) questionnaires were discarded because the students indicated that they did not answer all the questions honestly or because there were five or more logically inconsistent answers or extreme values on the questionnaire. An additional $171(11 \%)$ questionnaires were omitted from this analysis because of incomplete data for one or more of the variables examined in this report. Therefore, results are reported for 1265 students aged $10-19$ years, $95 \%$ of whom were white.

All variables reported here have a minimum $\kappa$ statistic of 0.70 for test-retest reliability, which indicates very good reliability for these items; it was not necessary to exclude any variable because of an unacceptably low $\kappa .{ }^{12}$ Regarding external validity, the $95 \%$ confidence intervals (CI) for reported tobacco use by age in this study was found to overlap those for adolescents in the 1996 Monitoring of the Future study. ${ }^{13}$
SUSCEPTIBILITY TO SMOKING AND SMOKING EXPERIENCE

Pierce and colleagues have shown that a variable which describes attitudes toward smoking (termed "susceptibility to smoking") can be combined with measures of experience to predict more accurately later smoking behaviour. ${ }^{1415}$ Susceptibility to smoking is determined from responses when asked: "How likely are the following? (1) I will smoke a cigarette in the next six months; (2) I would smoke a cigarette if a friend offered me one." Any individual who cannot definitely rule out smoking in the future by answering "definitely not" for both of these statements is susceptible. Prospective studies show that susceptible individuals are more likely to increase their consumption of cigarettes in the future, regardless of current experience category. ${ }^{16}$

Lifetime smoking experience was determined by students' answers to two questions: "Have you ever tried smoking cigarettes, even a few puffs?" and "How many cigarettes have you smoked in your whole life?" "Never smokers" were defined as those who answered "no" and "none", respectively. "Experimental smokers" were those who had smoked fewer than 100 cigarettes and "smokers" were those who had smoked 100 or more.

For students in the initiation phase of smoking (0-99 cigarettes lifetime), we modelled phases of smoking uptake by creating a four category ordinal measure that categorised individuals based on their lifetime smoking experience and susceptibility to smoking. The categories for this smoking uptake index are: never smoker and not susceptible; never smoker and susceptible; experimental smoker and not susceptible; and experimental smoker and susceptible.

\section{EXPOSURE VARIABLES}

We evaluated CPI ownership through three questions. First we asked, "Do you own something that has a cigarette brand on it, such as a T shirt, a backpack, or a hat?" (responses: yes, no, don't know). Next we asked, "If you own something with a cigarette brand on it, what is it?" (responses: T shirt or sweatshirt, backpack, windbreaker or jacket, lighter, hat, other, don't own something with the name of a cigarette brand on it). Finally we assessed brand through a write-in question, "What are the brand names on the items that you own?". To assess preference we asked the open ended question, "If you were to buy a pack of cigarettes, what brand do you think you would buy?".

Social environment is a key element in adolescents' decisions to smoke. In evaluating the dose-response relation between CPI ownership and smoking behaviour, we controlled for the effects of other individual and environmental characteristics known to be associated with smoking: friends and family smoking as constructed by Evans and colleagues (none, family only, friends only, family and friends) ${ }^{5}$; perceived prevalence of smoking, grade in school, sex, and school performance. Family smoking was defined by a "yes" response to any of the following three questions: "Do any 
Table 1 Number of cigarette promotional items owned by student characteristics

\begin{tabular}{|c|c|c|c|c|}
\hline Characteristic & Sample size & $\%$ & $\begin{array}{l}\text { Mean number of } \\
\text { CPIs }(S D)\end{array}$ & $p$ Value \\
\hline Total & 1265 & 100 & $0.63(1.2)$ & \\
\hline \multicolumn{5}{|l|}{ Number of CPIs } \\
\hline 0 & 859 & 68.0 & 0 & \\
\hline 1 & 211 & 16.7 & 1 & \\
\hline 2 & 82 & 6.5 & 2 & \\
\hline 3 & 57 & 4.5 & 3 & \\
\hline 4 & 24 & 1.9 & 4 & \\
\hline 5 & 23 & 1.8 & 5 & \\
\hline 6 & 7 & 0.6 & 6 & \\
\hline \multicolumn{5}{|l|}{ Grade } \\
\hline 6 & 67 & 5.3 & $0.67(1.3)$ & 0.35 \\
\hline 7 & 164 & 13.0 & $0.48(1.0)$ & \\
\hline 8 & 148 & 11.7 & $0.67(1.0)$ & \\
\hline 9 & 245 & 19.4 & $0.60(1.1)$ & \\
\hline 10 & 230 & 18.2 & $0.75(1.3)$ & \\
\hline 11 & 219 & 17.3 & $0.69(1.4)$ & \\
\hline 12 & 192 & 15.2 & $0.55(1.1)$ & \\
\hline \multicolumn{5}{|l|}{ School performance } \\
\hline Excellent & 372 & 29.4 & $0.38(0.9)$ & $<0.0001$ \\
\hline Good & 517 & 40.9 & $0.59(1.2)$ & \\
\hline Average or below & 376 & 29.7 & $0.94(1.4)$ & \\
\hline \multicolumn{5}{|l|}{ Sex } \\
\hline Female & 662 & 52.3 & $0.55(1.0)$ & 0.007 \\
\hline Male & 603 & 47.7 & $0.73(1.3)$ & \\
\hline \multicolumn{5}{|l|}{ Most kids smoke? } \\
\hline Disagree & 380 & 30.0 & $0.4 \quad(0.9)$ & $<0.0001$ \\
\hline Agree & 625 & 49.4 & $0.6 \quad(1.1)$ & \\
\hline Strongly agree & 260 & 20.6 & $1.1(1.5)$ & \\
\hline \multicolumn{5}{|l|}{ Environmental smoking } \\
\hline None & 145 & 11.5 & $0.16(0.4)$ & $<0.0001$ \\
\hline Family only & 104 & 8.2 & $0.37(0.9)$ & \\
\hline Friends only & 343 & 27.1 & $0.29(0.8)$ & \\
\hline Family and friends & 673 & 53.2 & $0.94(1.4)$ & \\
\hline
\end{tabular}

of your brothers or sisters smoke cigarettes, cigars, or pipes?", "Does your mother or stepmother smoke cigarettes, cigars, or pipes?", and "Does your father or stepfather smoke cigarettes, cigars, or pipes?" Friend smoking was defined by a "yes" response to the following question: "Do any of your friends smoke cigarettes?" School was also included as a variable in all models.

STATISTICAL ANALYSIS

We tabulated mean CPI ownership by grade in school, school performance, sex, perceived perception of peer student smoking, and exposure to peer and family smoking, and tested the association between the number of CPI items owned and these confounding variables using Poisson regression analysis.

We modeled "smoking" based on lifetime smoking experience, comparing smokers with all others using over dispersed logistic regression. ${ }^{17}$ "Over dispersion" is a technique which relaxes the variance restriction imposed by standard logistic regression and allows for models in which student behaviour may cluster. Compared with standard logistic regression, use of this technique often results in conservative significance tests for all estimates, widening the $95 \% \mathrm{CI}$.

Table 2 CPI brand and cigarette brand preference among never smokers

\begin{tabular}{lllll}
\hline \multicolumn{5}{c}{ Brand preference (what brand would you buy?) } \\
\hline CPI Brand & Don't know & Marlboro & Camel & Other \\
None & $431(89.4)$ & $24(5.0)$ & $22(4.6)$ & $5(1.0)$ \\
Marlboro only & $41(77.4)$ & $10(18.9)$ & $1(1.9)$ & $1(1.9)$ \\
Camel only & $16(84.2)$ & $0(0.0)$ & $3(15.8)$ & $0(0.0)$ \\
Marlboro and Camel & $8(53.3)$ & $5(33.3)$ & $1(6.7)$ & $1(6.7)$ \\
Other & $4(100.0)$ & $0(0.0)$ & $0(0.0)$ & $0(0.0)$ \\
\hline
\end{tabular}

Since a dose-response association between CPI ownership and being a smoker could be an expression of an adolescent who acquired these items after becoming a smoker, we also modelled the association between CPI ownership and a higher level of smoking uptake among never smokers and experimental smokers using proportional odds models, with the smoking uptake index as the dependent variable. ${ }^{11}$ Our previous study showed significantly higher likelihood of experimentation only among adolescents who owned CPIs in grades 6-9. ${ }^{6}$ Similarly, there was no dose-response for the older children, so we confined our analysis of a dose-response for experimentation to never smokers and experimental smokers in grades $6-9(n=543)$.

Proportional odds models evaluate the likelihood of being further along the smoking uptake process given CPI ownership after adjusting for confounders. Proportional odds models give cumulative odds ratios modelling the probability of being in any higher category on the smoking uptake index, not just the adjacent one. With an ordered dependent variable, these models have the advantage of retaining information that would be lost by combining the data into two arbitrary groups. We modelled CPI ownership by grade in school using interaction terms, in order to determine if the association between ownership and smoking uptake was strongest during the period of smoking initiation (grades 6-9). In all models, changes in deviance and residual plots were used to assess model fit, and standard errors were scaled using the square root of deviance based dispersion.

\section{Results}

NUMBER OF CPIS OWNED BY STUDENTS

Of 1265 students, approximately one third owned CPIs, with percent ownership being equally distributed by grade in school at approximately $30 \%$ of students (table 1 ). In contrast, the percentage of students who were smokers climbed as grade increased, from 3\% of sixth graders to a high of $32 \%$ of 12 th graders. These data suggest that CPIs were being acquired by students well before they became smokers, probably through friends and family members. ${ }^{6}$

\section{BRAND OF CPI AND BRAND OF CIGARETTE} SMOKED

Brand of CPI owned was significantly associated with brand preference among never smokers, experimental smokers, and smokers $\left(\chi^{2}, \mathrm{p}<0.0001, \mathrm{p}=0.023\right.$, and $\mathrm{p}=0.002$, respectively). Results are shown for never smokers in table 2. Among never smokers who did not own CPIs, only 5\% chose Marlboro or Camel when asked to envision the cigarette brand they would buy. In contrast, $19 \%$ of those who owned a Marlboro CPI chose the Marlboro brand and $16 \%$ of those who owned a Camel CPI chose the Camel brand. 


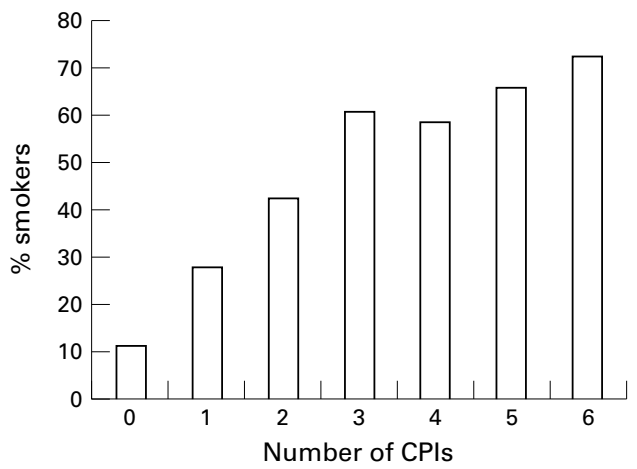

Figure 1 Crude dose-response: percentage of students ( $n=$ 1265) who are smokers (have smoked $\geqslant 100$ cigarettes lifetime) versus number of cigarette promotional items (CPIs) owned.

DOSE-RESPONSE BETWEEN CPI OWNERSHIP AND SMOKING

The number of CPIs owned by students ranged from $0-6$, with a mean of 0.63 . Mean CPI ownership was also equally distributed by grade in school. Males, students with poor school performance, those who perceived higher levels of student smoking, and those with higher exposure to peer and family smoking all owned significantly higher numbers of CPIs (table 1). The crude dose-response between CPI ownership and the proportion of students who were smokers ( $\geqslant 100$ cigarettes lifetime) is shown in fig 1 . There is a direct linear relation between the number of CPIs owned and the percentage of students who are smokers, with $10 \%$ of those who did not own a CPI being smokers compared with $70 \%$ for those who own six CPIs $(p<0.0001)$. Moreover, among daily smokers, there was a direct relation between number of CPIs owned and daily cigarette consumption. For example, among daily smokers who owned none, three, and five or more CPIs, the percentage who smoked one pack of cigarettes per day or more was $10 \%, 26 \%$, and $40 \%$, respectively (test for trend, $\mathrm{p}<0.0001$ ).

The dose-response remained after controlling for grade in school, sex, school performance, perceived prevalence of smoking, peer smoking, and family smoking. Compared with those who did not own a CPI, the likelihood of being a smoker increased from an odds ratio (OR) of 2.7 (95\% CI 1.7 to 4.1 ) for those who owned one CPI, to 3.4 (95\% CI 1.9 to 5.9) for those owning two CPIs, and 8.4

Table 3 Adjusted odds ratio (OR) of being a smoker (lifetime smoking $\geqslant 100$ cigarettes) according to student characteristics $^{\star}(n=1265)$

\begin{tabular}{|c|c|c|c|}
\hline Student characteristic & Adjusted $O R$ & $95 \% C I$ & p Value \\
\hline \multicolumn{4}{|c|}{ Number of CPI's owned } \\
\hline 0 & Reference & & \\
\hline 1 & 2.7 & 1.7 to 4.1 & $<0.0001$ \\
\hline 2 & 3.4 & 1.9 to 5.9 & $<0.0001$ \\
\hline$\geqslant 3$ & 8.4 & 5.0 to 14.2 & $<0.0001$ \\
\hline \multicolumn{4}{|c|}{ Friend and family smoking } \\
\hline None & reference & & \\
\hline Family only & 2.5 & 0.2 to 26.1 & 0.22 \\
\hline Friends only & 4.7 & 0.6 to 36.4 & 0.03 \\
\hline Family and friends & 17.7 & 2.3 to 129.9 & 0.006 \\
\hline
\end{tabular}

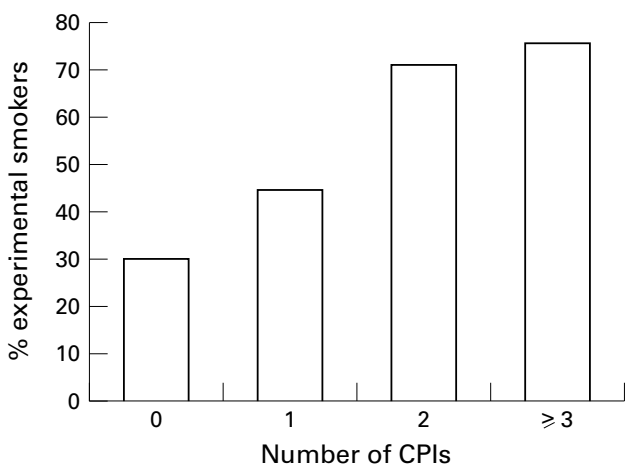

Figure 2 Crude dose-response: percentage of students in grades 6-9 $(n=543)$ who are experimental smokers (have smoked 1-99 cigarettes lifetime) versus number of cigarette promotional items (CPIs) owned. This figure excludes those who have smoked $\geqslant 100$ cigarettes lifetime.

(95\% CI 5.0 to 14.2) for those owning three or more CPIs (table 3). Exposure to both family and peer smoking was also associated with higher likelihood of being a smoker.

ASSOCIATION OF CPI OWNERSHIP WITH SMOKING UPTAKE AMONG NEVER AND EXPERIMENTAL SMOKERS

Over three fourths of the sample $(n=1008)$ were in the initiation phase of smoking uptake (0-99 cigarettes lifetime), of whom 543 were in grades 6-9. There was no association between CPI ownership and higher levels of experimentation for students in grades 10-12 (results previously reported). Among sixth to ninth graders, there was a crude dose-response between the number of CPIs owned and the percentage of experimental smokers (fig 2), with experimentation rates rising from $30.5 \%$ of those who did not own a CPI to $76.2 \%$ of those who owned three or more.

The dose-response between CPI ownership and higher levels of experimentation persisted even after adjusting for the effects of grade in school, sex, school performance, perceived prevalence of smoking, peer smoking, and family smoking (table 4). Compared with those who did not own a CPI, those owning one had an adjusted cumulative odds ratio for higher levels of experimentation of 1.7 (95\% CI 1.1 to 2.6). The cumulative odds ratios for those owning two and three or more CPIs were 2.5 (95\% CI 1.2 to 5.1 ) and 4.8 (95\% CI 1.9 to

Table 4 Adjusted cumulative odds ratio (OR) of a student being further along the smoking uptake process according to student characteristics * among never smokers and experimental smokers in grades $6-9(n=543)$

\begin{tabular}{|c|c|c|c|}
\hline Student characteristic & $\begin{array}{l}\text { Adjusted } \\
\text { cumulative OR }\end{array}$ & $95 \% C I$ & $p$ Value \\
\hline \multicolumn{4}{|c|}{ Number of CPI's owned } \\
\hline 0 & Reference & & \\
\hline 1 & 1.7 & 1.1 to 2.6 & 0.03 \\
\hline 2 & 2.5 & 1.2 to 5.1 & 0.01 \\
\hline$\geqslant 3$ & 4.8 & 1.9 to 12.2 & 0.001 \\
\hline \multicolumn{4}{|c|}{ Friend and family smoking } \\
\hline None & Reference & & \\
\hline Family only & 1.4 & 0.7 to 2.8 & 0.35 \\
\hline Friends only & 3.3 & 1.9 to 5.8 & $<0.0001$ \\
\hline Family and friends & 5.5 & 3.1 to 9.8 & $<0.0001$ \\
\hline
\end{tabular}


12.2), respectively. In this analysis, peer smoking was also associated with higher levels of experimentation.

\section{Discussion}

This study offers compelling evidence for a dose-response relation between a simple ordinal measure of exposure to cigarette promotional campaigns and higher likelihood of experimental and established smoking among adolescents. The odds ratios for CPI ownership in both the smoker and the experimenter regressions suggest a CPI effect that is similar to peer smoking. The demonstration of a dose-response relation provides further support of a causal relation between cigarette promotional activities and the uptake of smoking in adolescents.

Our results extend the work of Evans and colleagues $^{5}$ and Pierce and associates ${ }^{9}$ who demonstrated a graded response between a receptivity to cigarette marketing index and susceptibility to becoming a smoker among never smokers ${ }^{5}$ and greater levels of experimentation over time. ${ }^{9}$ In those studies, ownership or willingness to wear a cigarette promotional item was the highest level in the index. Adolescents were categorised into intermediate levels if they could identify tobacco advertising messages or had a favourite brand. Our study evaluates and confirms a dose-response within the highest category of their receptivity to cigarette marketing index.

Because of the cross sectional nature of this study, we are unable to infer directly that ownership of cigarette promotional items precedes smoking. However, several aspects of our research suggest that exposure to cigarette promotional items comes before the adoption of the smoking in this sample. First, the prevalence of smoking rises with grade in school, but the prevalence of ownership of cigarette promotional items is stable across grades at around $30 \%$. If these items were acquired during the later phases of initiation, for example, by adolescents who were smoking heavily enough to purchase the items by saving value added coupons, one would expect the prevalence of ownership to rise with grade and lag behind the adoption of smoker status. Second, the ownership of these items is associated with higher levels of experimentation among the youngest adolescents in this sample. Ownership is also significantly associated with attitudes which predict smoking (susceptibility) and cigarette brand preference among the never smokers in this sample.

At face value, the measurement of the number of cigarette promotional items an adolescent owns seems to be a pure measure of exposure to tobacco marketing. To the extent that acquisition and use of cigarette promotional items affects the adolescent's self identity as a smoker this may be true. The use of clothing and personal items as a means of consolidating identity is consistent with studies of consumer behaviour in adolescents. ${ }^{18-20}$ But people also use symbolic markers such as clothing, hairstyles, and tattoos to communicate their social identities. ${ }^{21}$ Clothes define group affiliation and express core aspects of identity, such as personal values, beliefs, and preferences. In this way, ownership of cigarette promotional items could be the means through which adolescents express values attained from other aspects of their social environment. However, the association between cigarette promotional item ownership and smoking uptake appears to be independent of measures of smoking in the social environment. Because this association is not confounded by friends or family smoking or perceived prevalence of smoking, we suggest it has a socialising effect above and beyond these factors. It is also likely that both directions are operational; acquisition and use of cigarette promotional items affects and reinforces self identity as a smoker, which in turn causes the adolescent to pursue further the collection of more promotional items.

In summary, the more cigarette promotional items an adolescent owns, the higher the likelihood of being a smoker. The same is true for experimentation with tobacco and susceptibility to tobacco use among never and experimental smokers. These findings support a dose-response relation between cigarette promotional item ownership and smoking uptake among adolescents, and add to evidence supporting a causal association between tobacco promotional activities and smoking in the adolescent population.

This work was supported by National Cancer Institute grants CA-67538 and CA-23108.

1 Tye J, Warner K, Glantz S. Tobacco advertising and consumption: evidence of a causal relationship. $\mathcal{F}$ Public Health Policy 1987;8:492-508.

2 Coughlin PJ, Janecek FJ, Weiss-Bershad M. A review of R.F Reynolds' internal documents in Mangini $v$ R.F Reynolds Tobacco Co, Civil no. 939359. San Francisco: Milberg Weiss Bershad Hynes \& Lerach LLP; 1997.

3 Hennekens CH, Buring JE. Epidemiology in medicine. Boston: Little Brown and Company; 1987.

4 Altman D, Levine D, Coeytaux M, Slade J, Jaffe R. Tobacco promotion and susceptibility to tobacco use among adolescents aged 12 through 17 years in a nationally representative sample. Am $\mathcal{F}$ Public Health 1996;86:1590-3.

5 Evans N, Farkas A, Gilpin E, Berry C, Pierce J. Influence of tobacco marketing and exposure to smokers on adolescent susceptibility to smoking. I Natl Cancer Inst 1995; 87:1538-45.

6 Sargent JD, Dalton MA, Beach M, Bernhardt A, Pullin D, Stevens $M$. Cigarette promotional items in public schools. Arch Pediatr Adolesc Med 1997;151:1189-96.

7 Schooler C, Feighery E, Flora JA. Seventh graders' self-reported exposure to cigarette marketing and its relationship to their smoking behavior. Am $\mathcal{f}$ Public Health 1996;86:1216-21.

8 Armstrong BK, de Klerk NH, Shean RE, Dunn DA, Dolin PJ. Influence of education and advertising on the uptake of smoking by children. Med 7 A ust 1990;152:117-24.

9 Pierce JP, Choi WS, Gilpin EA, Farkas AJ, Berry CC. Tobacco industry promotion of cigarettes and adolescent Tobacco industry promotion of cig

10 US Department of Health and Human Services. Preventing tobacco use among young people. A report of the Surgeon General, 1994. Atlanta, Georgia: Public Health Service, Centers for Disease Control and Prevention, Office on Smoking and Health, 1994. (US Government Printing Office Publication No S/N 017-001-00491-0.)

11 Stevens M, Youells F, Whaley F, Linsey S. Drug use prevalence in a rural school-aged population: the New Hampshire survey. Prev Med 1995;11:105-13.

12 Landis JR, Koch GG. The measurement of observer agreement for categorical data. Biometrics 1977;33:671-9.

13 Bachman JG, Johnston LD, O'Malley PM. Monitoring the future: questionnaire responses from the nations's high school seniors 1996. Ann Arbor, Michigan: Institute for Social Research, University of Michigan; 1996.

14 Pierce J, Farkas A, Evans N. Tobacco use in California 1992: a focus on preventing uptake in adolescents: Sacramento;

15 Pierce J, Choi W, Gilpin E, Farkas A, Merritt RG. Validation of susceptibility as a predictor of who takes up smoking in the United States: San Diago: University of California at San Diego, 1995. 
16 Choi WS, Pierce JP, Farkas AJ, Gilpin EA, Farkas AJ, Berry CC. Which adolescent experimenters progress to established smol

17 McCullagh P, Nelder JA. Generalized linear models, 2nd ed. London: Chapman and Hall, 1989.

18 Eicher JB, Baizerman S, Michelman J. Adolescent dress, part II: a qualitative study of suburban high school students. Adolescence 1991;26:679-86.
19 Gunter B, Furnham A. Children as consumers. A psychological analysis of the young people's market. London: Routledge, 1998.

$20 \mathrm{McNeal}$ JU. Children as consumers. Insights and implications. Lexington: Lexington Books, 1987.

21 Deaux K. Social identification. In: Higgins ET, Kruglanski AW, eds. Social psychology: handbook of basic principles. New York: Guilford, 1996:777-98.

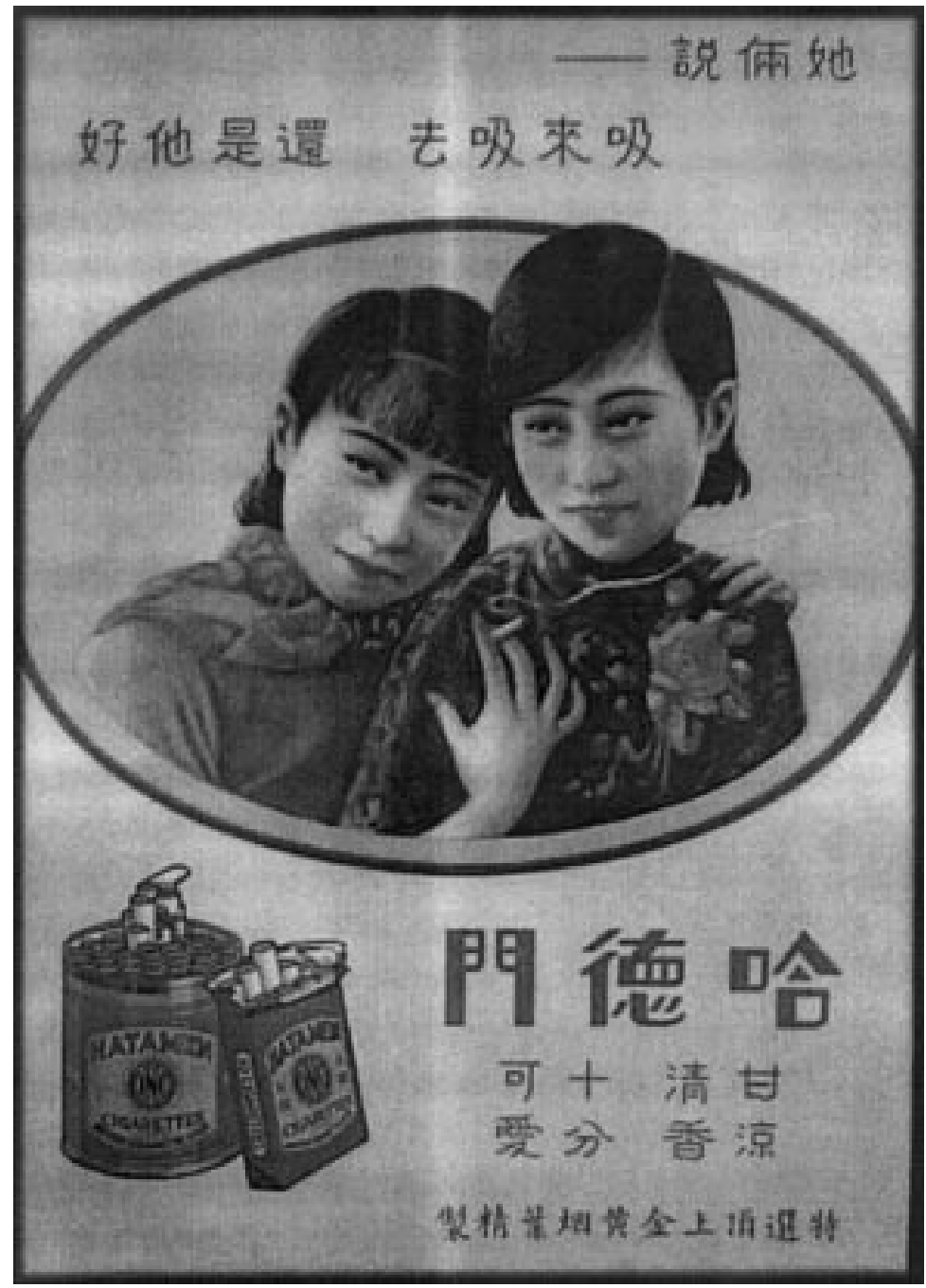

Vintage Chinese cigarette advert 